\title{
The Effect of Ethyl Methane Sulfonate (EMS) on The In Vitro Shoot Regeneration of Vetiver (Vetiveria zizanioides [L.] Nash)
}

\author{
Wahyu Widoretno*, Serafinah Indriyani \\ Department of Biology, Faculty of Mathematics and Natural Sciences, University of Brawijaya, Malang
}

\begin{abstract}
Production of vetiver in Indonesia is low, and its oil quality is not in line with market demand due to the low quality of plant raw materials. In vitro mutagenesis using ethyl methanesulfonate (EMS) has the potential to produce superior vetiver variants. This study aimed to determine the effect of EMS on the growth and shoot formation of in vitro vetiver plants. In vitro mutagenesis was performed by culturing in vitro shoots on MS medium containing EMS with various concentrations $(0.02 ; 0.04 ; 0.06 ; 0.08 ; 0.1 \%)$ for 4 weeks. The results showed that the addition of $0.02-0.1 \%$ EMS to the medium affected on in vitro shoot growth and the ability to form new shoots. EMS increased the percentage of dead explants and decreased the average number of shoots, the number of shoots formed per explant, and the shoot fresh weight. The higher the EMS concentration in the medium, the smaller the percentage of survived explants and the lower ability to form new shoots with the average number of shoots formed less. The percentage of survived explants on the medium without the addition of EMS and on the medium with the addition of EMS with low concentrations of 0.02 and $0.04 \%$ reached $100 \%$ with an average number of shoots formed ranging from $8.5-10$ shoots/explant. Meanwhile, the percentage of survived explants on medium with the addition of EMS with a high concentration of 0.08$0.1 \%$ was only $12.5-25 \%$ with an average number of shoots formed was less than 2 shoots/explant.
\end{abstract}

Keywords: EMS, in vitro shoots, Vetiveria zizanioides.

\section{INTRODUCTION}

Vetiver oil derived from vetiver (Vetiveria zizanioides [L.] Nash) is one of the essential oils with a high market demand. It is used as a fixative in the perfume industry, a component mixture in the soap and cosmetics industry, and aromatherapy [1]. The use of vetiver oil in various industries is due to the presence of various chemical components of vetiver oil, namely vetiverol, vetivone, khusimone, khusimol, vetivene, khositone, terpenes, benzoic acid, triterpene-4-ol, $\quad \beta$-humulene, epizizianal, vetivenyl vetivenate, iso khusimol, $\beta$-vetivone, and vetivazulene [2].

Vetiver production in Indonesia has not been able to meet the needs of vetiver oil because its production is low and it is not in accordance with market demand [3]. Its low quality is due to an accumulation of the low and non-uniform quality of essential plant raw materials as well as the less optimal refining process [4]. Therefore, to improve the quality of raw materials and oil yield, it is necessary to develop superior vetiver plant seeds.

In vitro mutagenesis, a combination of mutation induction and in vitro culture techniques is very effective for plant breeding

\footnotetext{
* Correspondence address:

Wahyu Widoretno

Email : wahyu_widoretno@yahoo.com

Address : Dept. Biology, Brawijaya University, Malang 65145
}

programs because it accelerates the production of mutants. In addition to the high mutation frequency, in vitro mutagenesis also provides many choices of plant materials used for mutagen treatment such as in vitro axillary shoots, organs, tissues, protoplasts and cells which are more suitable for mutation induction techniques compared to in vivo shoots $[5,6]$. In vitro mutagenesis with EMS has been used successfully to obtain mutants in Saintpaulia (African violet) [7], Stevia (Stevia rebaudiana) [8], and cotton (Gossypium hirsutum L.) [9].

Besides producing variations in morphological characteristics, several studies showed that chemical mutagens EMS in high concentrations had an inhibitory effect on explant survival, callus formation, germination, shoot initiation and proliferation, root initiation, and plantlet regeneration $[9,10,11]$. Therefore, it is necessary to evaluate the effect of EMS on in vitro shoot regeneration in vetiver plants.

\section{MATERIAL AND METHOD \\ Plant Material}

Vetiveria zizanioides (L) Nash plants were collected from Sengklek, Pamalayan Village, Bayongbong District, Garut, West Java.

\section{Multiplication of In Vitro Shoots}

The source of explants used in this study was in vitro shoots obtained from crown explants. In vitro shoots were multiplied on MS medium with the addition of growth regulators NAA $0.1 \mathrm{mg} \cdot \mathrm{L}^{-1}$ and BA $1 \mathrm{mg} \cdot \mathrm{L}^{-1}$. The culture was incubated at 
$24^{\circ} \mathrm{C}$ in light conditions for four weeks. The in vitro shoots of vetiver was used as material for in vitro mutagenesis using EMS.

\section{Effect of EMS on Shoot Growth In Vitro}

In vitro mutagenesis was performed using EMS. Small clumps of vetiver shoot $(0.1 \mathrm{~g})$ were cultured on MS medium + NAA $0.1 \mathrm{mg} \cdot \mathrm{L}^{-1}+\mathrm{BA} 1$ mg. $\mathrm{L}^{-1}+\mathrm{EMS}$ with several concentrations (0; $0.02 ; 0.04 ; 0.06 ; 0.08 ; 0.1 \%$ ). Each mutagen treatment was repeated 10 times (10 bottles), with 5 clump shoots in each bottle. The cultures were incubated at $24^{\circ} \mathrm{C}$ in light conditions for 4 weeks. Each week, the growth of the culture was evaluated including the percentage of survived shoot explants, the percentage of explants forming shoots and the number of shoots formed. At the end of culture (4 weeks) the fresh weight of the shoots was measured.

\section{Data analysis}

The data were analyzed statistically using ANOVA (analysis of variance) and the differences among the mean values were compared with Duncan's Multiple Range Test (DMRT) $(P<0.005)$ using ver. 25 .

\section{RESULT AND DISCUSSION}

The addition of EMS in the medium affected the growth ability of in vitro shoots and the formation of new shoots (Fig. 1). In the medium without the addition of EMS, all in vitro shoots were able to grow and form new shoots, while the addition of EMS to the medium caused browning and death in some in vitro shoots and inhibited the formation of new shoots. The higher the EMS concentration in the medium, the more dead explants and the higher the inhibition of shoot growth in culture. Furthermore, the higher the EMS concentration in the medium, the less the ability of the explants to form new shoots.

All shoot explants cultured on MS medium with the addition of $0.1 \mathrm{mg} \cdot \mathrm{L}^{-1}$ NAA growth regulator combined with $1 \mathrm{mg} \cdot \mathrm{L}^{-1} \mathrm{BA}$ without the addition of EMS survived and were able to form new shoots. The addition of EMS to the medium affected the percentage of survived explants, the average number of shoots, the number of shoots formed per explant and the fresh weight of shoots (Fig. 2).

The longer the culture period, the higher the percentage of dead explants, but the average number of shoots and the number of shoots formed per explant increased. At 4 weeks of culture, the percentage of survived explants on the medium without the addition of EMS and in the medium with the addition of $0.02 \%$ and $0.04 \%$ EMS was $100 \%$, while the percentage of survived explants on the medium with the addition of higher EMS concentration, $0.06 \%$, was $65 \%$. The percentage of survived explants cultured on medium with a high EMS concentration, $0.08-0.1 \%$, was only around 12.5 $25 \%$ (Fig. 2A).

Besides affecting the percentage of survived explants, the addition of EMS to the medium inhibited the formation of new shoots. The fresh weight of shoot formed per explant on the control medium without the addition of EMS was $0.132 \mathrm{~g}$, while the fresh weight of shoot in the medium with the addition of 0.02 and $0.04 \%$ EMS was $0.115 \mathrm{~g}$ and $0.081 \mathrm{~g}$, respectively. Shoots formed on medium with higher EMS, 0.06-0.1\%, had a fresh weight of $0.046-0.061 \mathrm{~g}$ or less than half the fresh weight of shoots formed on the control medium without the addition of EMS (Fig. 2B).

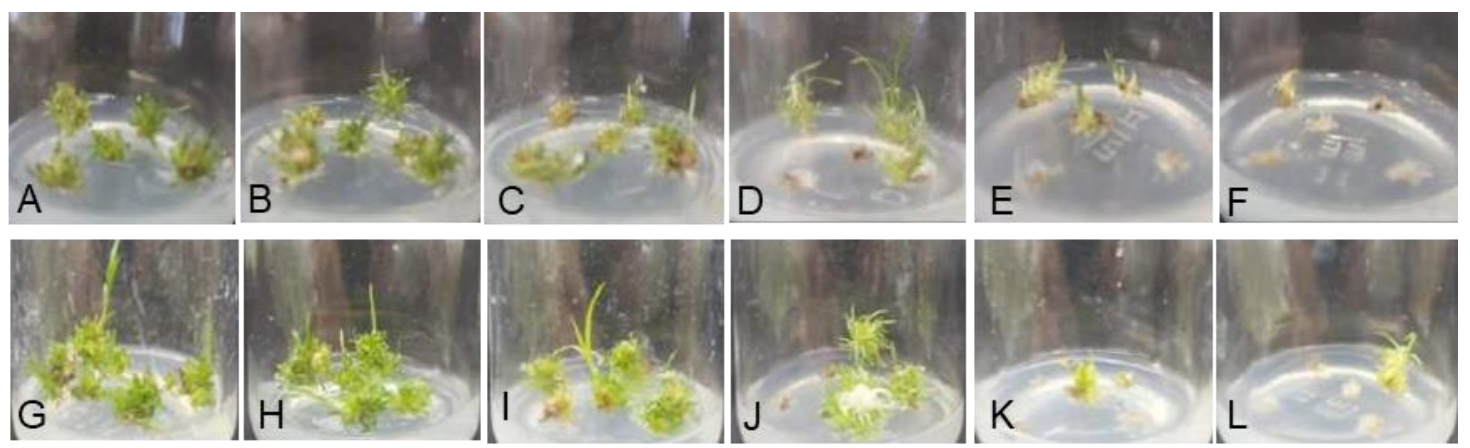

Figure 1. In vitro shoot explant growth response of Vetiveria zizanioides [L.] Nash to culture medium with the addition of EMS at 2 and 4 weeks of culture. A-F: 2 weeks, G-H: 4 weeks. A\&G. without EMS (control), B\&H. EMS 0.02\%, C\&I. EMS $0.04 \%$, D\&J. EMS 0.06\%, E\&K. EMS 0.08\%, F\&L. EMS 0.1\%. 

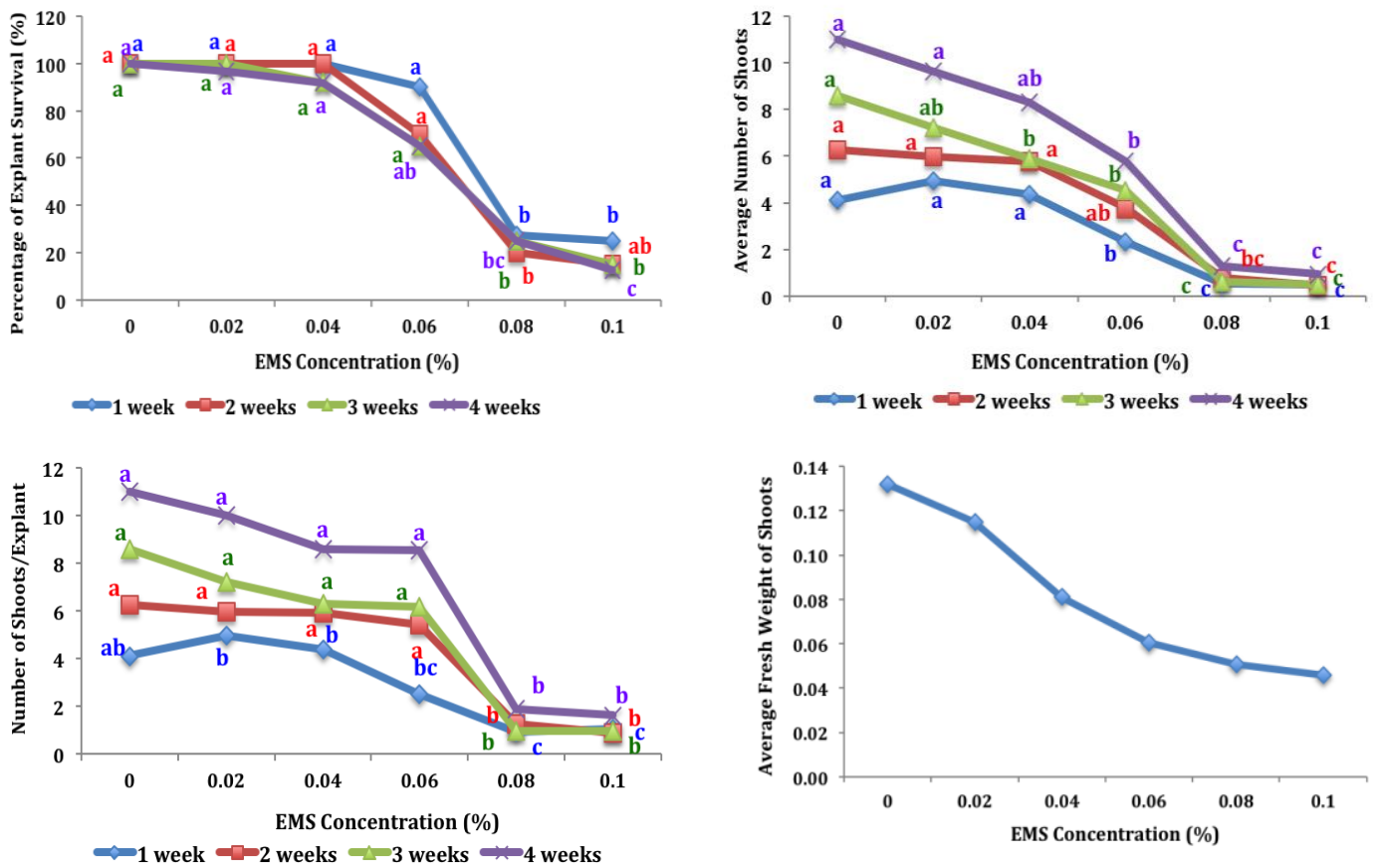

Figure 2. The effect of EMS on the medium on in vitro shoot growth of Vetiveria zizanioides [L.] Nash. A. Percentage of explant survival, B. Average number of shoots, C. Number of shoots/explant, D. Average of fresh weight/explant. Values followed by same letters for each culture period are not significantly different at $5 \%$ level as determined by Duncan's test (DMRT).

At the end of culture or 4 weeks after culture, the average number of shoots and the number of shoots formed per explant on the control media without the addition of the EMS mutagen was 11 shoots, while the average number of shoots and the number of shoots formed per explant on the medium with the addition of EMS 0, 02-0.06\% ranged from 5.8-9.6 shoots (8.5-10 shoots/ explant). The average number of shoots and the number of shoots formed per explant on the medium with the addition of $0.08-0.1 \%$ EMS was between $0.9-1.3$ shoots (1.6-1.9 shoots/explant) (Fig. 2C and 2D).

EMS mutagen added in the medium could reduce the viability of explants, growth and regeneration of vetiver shoots, and the higher the mutagen concentration, the higher the inhibition level of shoot regeneration. This suggests that the EMS mutagen in addition to inducing genetic variability is also toxic to in vitro shoot explants and causes disturbance toward some of the growth activities of the in vitro shoots of vetiver plants.

The effect of EMS on the inhibition of various growth parameters has been previously reported in some plants [8,11,12]. Immersion of 0.1-0.3\% EMS for 30 minutes inhibited callus formation and shoot regeneration in Stevia [8]. EMS also reduced the percentage of survived explants, in vitro shoot regeneration and proliferation of chrysanthemums [11].

The frequency of shoot induction showed a decreasing trend with an increase in mutagen concentrations in citrus, stevia, and chrysanthemum $[8,11,12]$. There was a decrease in the number of regenerated shoots and shoot height and number of leaves with increasing concentrations of chemical mutagens $[12,13]$.

Explant mortality cultured on medium with high EMS concentrations could be due to the toxic effect of mutagens [14]. Meanwhile, previous study mentioned that mutagens might cause disruption of hormone activity, especially cytokinins and physiological disturbances in shoot growth [11]. Physiological disturbances are mainly related to hormones and chromosome aberrations, which can cause inhibition of shoot initiation and proliferation and root induction.

\section{CONCLUSION}

The addition of EMS in the culture medium affect the ability of in vitro shoot growth and regeneration. EMS as mutagenic chemical reduce explants mortality and shoot regeneration, number of shoots formed per explant, shoots fresh weight and inhibit the formation of new 
shoots. This suggests that addition of EMS mutagen not only induce genetic variability but also toxic to in vitro shoot explants and causes disruption of some of the growth activities of in vitro shoots of vetiver plants.

\section{REFERENCES}

[1] Inggrid, M., I. Levana, H. Djojosubroto. 2010. Perolehan dan karakteristik minyak akar wangi (Vetiveria zizanioides) hasil hidrodistilasi. Seminar Rekayasa Kimia dan Proses. Universitas Diponegoro. Semarang.

[2] Kumar, S.K., K.G. Gayathri, T. Kripa, Prathyusha. 2018. Preminilary phytochemical analysis and in vitro pharmacological evaluation of phytosterol rich fraction from Vetiveria zizanoides Nash. Int. J. Res. Pharm.Sci. 9(3). 922-930.

[3] Kardinan, A. 2005. Tanaman penghasil minyak atsiri komoditas wangi penuh potensi, $1^{\text {st }}$ Ed. Agromedia Pustaka. Jakata.

[4] Mulyono. 2012. Peningkatan mutu dan efisiensi produksi minyak akar wangi melalui teknologi penyulingan dengan tekanan uap bertahap. Buletin Teknologi Pascananen Pertanian. 8(1). 35-47.

[5] Penna, S., S.B. Vitthal, P.V. Yadav. 2012. In vitro mutagenesis and selection in plant tissue cultures and their prospects for crop improvement. Bioremediation, Biodiversity and Bioavailability. Global Science Books. 6(1). 6-14.

[6] Predieri, S. 2001. Mutation induced and tissue culture in improving fruits. Plant Cell Tiss. Organ Cult. 64. 185-210.

[7] Fang, J.Y., S. Traore. 2011. In vitro mutation induction of saintpaulia using ethyl methanesulfonate. Hortscience. 46(7). 981984.

[8] Gerami, M. H. Abbaspour, V., Ghasemiomran, H. Pirdashti. 2017. Effects of ethyl metahesulfonate on morphological and physiological traits of plant regenerated from stevia (Stevia rebaudiana Bertoni) Calli. Appl. Ecol. Environ. Res. 15(3). 373385.

[9] Muthusamy, A. , J. Narayanasamy. 2011. In vitro induction of mutation in cotton (Gossypium hirsutum L.) and isolation of mutants with improved yield and fiber characters. Acta Physiol. Plant. 33(5). 17931801.

[10] Kona, P., H.M. Kumar, K.H.P. Reddy, D.M. Reddy, N.P.E. Reddy, P. Latha, M.S. Balaji. 2019. Effect of 2,4-D and EMS on in vitro regeneration in sugarcane cultivar, Co86032. Intl. J. Curr. Microbiol. Appl. Sci. 8(3). 1228-1236

[11] Padmadevi, K., M. Jawaharlal, 2011. Induction of in vitro mutation in chrysanthemum (Dendranthema grandiflora Tzvelev) Ray Florets (var. Ravi Kiran) using gamma rays and EMS. Floriculture Ornamental Biotech. 5(1). 74-77.

[12] Kaur, S. 2015. Effect of mutagens on regeneration and growt of in vitro grown epicotyl segments of rough lemon seedlings (Citrus jambhiri Lush). J. Appl. Nat. Sci. 7(1). 459-465

[13] Kashtwari, M., A.A. Wani, M.K. Dhar, S. Jan, A.N. Kamili. 2018. Development of an efficient in vitro mutagenesis protocol for genetic improvement of saffron (Crocus sativus L.). Physiol. Mol. Biol. Plants. 24(5). 951-962.

[14] Datta, SK., P. Misra, A.K.A Mandal. 2005. In vitro mutagenesis a quick method for establishment of solid mutant in chrysanthemum. Curr. Sci. 88(1). 155-158. 